\title{
Suppression of Hydrogen-induced Damage in Friction Stir Welded Low Carbon Steel Joints
}

\author{
Yufeng Sun*, Hidetoshi Fujii, Hisashi Imai, Katsuyoshi Kondoh \\ Joining and Welding Research Institute, Osaka University, Ibaraki, Japan
}

\begin{abstract}
:
Hydrogen-induced damage including blister and cracking in friction stir welded low carbon steel were evaluated by the cathodic hydrogen charging method. After hydrogen charging for 2 hours, irreversible dome-shaped blisters and internal cracking began to appear on the surface of the base metal. However, after hydrogen charging for 16 hours, cracking formed along the thermo-mechanically affected zone boundary, while the blisters or cracking were hardly observed in the stir zone. In addition, the stir zone showed a plasticity reduction from $38 \%$ to $28 \%$, much less than that of the base metal reduced from $48 \%$ to $2 \%$.
\end{abstract}

Keywords: Hydrogen embrittlement; Hydrogen blister; Friction stir welding; Stir zone; Cathodic hydrogen charging

\footnotetext{
* Yufeng Sun (Y.F. Sun), Joining and Welding Research Institute, Osaka University, Japan Tel:81-6-68798653; Email: yfsun@jwri.osaka-u.ac.jp
} 


\section{Introduction}

Hydrogen embrittlement (HE) is defined as the deterioration of the mechanical properties resulting from the introduction of hydrogen into the materials by various methods including hydrogen-induced cracking (HIC), hydrogen blistering, stress corrosion cracking (SCC), etc. HE is a long-term problem, which has widely occurred during solidification, heat treatment, or a cathodic reaction. A special case is fusion welding, in which the atomic hydrogen formed during welding dissolves in the liquid metal of the weld. After solidification, some of the dissolved hydrogen will precipitate and often leads to the formation of cracks in the heat affected zone (HAZ) adjacent to the weld. It was found that absorbed atomic hydrogen migrating in the steel is accumulated on the fronts of non-metallic inclusions, microcracks or grain boundaries, and the recombination of atomic hydrogen into the molecular form causes an increase in the pressure of nascent $\mathrm{H}_{2}$ bubbles as well as nucleation and the development of microcracks. Opiela et al. studied the HE behavior of welded joints by cathodic hydrogen charge, and found that the welded joints are susceptive to hydrogen cracking in both the HAZ and fusion zone [1-3]. It was postulated that when hydrogen has entered a steel structure, the mechanism causing hydrogen embrittlement is the same, regardless of the hydrogen source. The microstructure of the steel is the main factor that dominates the susceptiveness of the material to HE. Although the structural characteristics of the materials that significantly influence the hydrogen induced cracking process are still not clearly understood, it is known that the phase constitution, grain boundary character and crystallographic texture, etc., affect the generation and propagation of hydrogen-induced crack in steel materials [47]. Generally, two of the most established mechanisms of hydrogen-induced failure of the materials are the hydrogen-enhanced local plasticity model (HELP) and the hydrogen-enhanced decohesion model (HEDE). The kind of mechanism that occurs during fracture strongly depends on the microstructure of the materials. For example, the fully ferritic steels essentially fracture through the HELP effect [8], while lath martensite steel was reported to undergo HELP associated with the HEDE effect [9]. Given the more complex microstructure, the HE behavior of the material maybe correspondingly complicated.

Friction Stir Welding (FSW) was invented by the Welding Institute (TWI) of the UK in 1991 with the original purpose of joining $\mathrm{Al}$ and $\mathrm{Al}$ alloys, since $\mathrm{Al}$ alloys are very difficult to weld by conventional fusion welding methods [10]. FSW is a solid-state joining technique, in which a rotating tool is plunged into the work-pieces and traverse along the weld path. In this way, the rotating tools can plastically deform (stir) and transport the surrounding material from the front to the back of the tools. As a result, the work-pieces can be stirred together to form a joint [11-12]. With the development of the FSW technique and the highly durable rotating tools, this technique has been expanded to many other high melting points metallic materials including $\mathrm{Cu}$, Ti, Fe and steels [13-15]. Recently, the FSW technique has been successfully used for the welding of high carbon steels, which are considered as unweldable materials by fusion welding methods due to the formation of the brittle martensitic phase [16-17]. Because of the complex materials flow during the FSW process [18], the resultant microstructure in the welded area is very complicated and significantly depended on the welding conditions and the material properties. For example, a very refined microstructure can be obtained in the stir zone (SZ) due to recrystallization. Since the FSW is carried out in the solid state, the problems caused by the dissolution of hydrogen into the materials may be significantly attenuated. Therefore, the friction stir welded joint must show different HE behavior comparing with its fusion welded counterpart. Recently, Khodir et al. first studied the blister suppression in a kind of high carbon steel by friction stir 
processing [19]. The prevention of the blister formation was proposed to be caused by the microstructure refinement and the prevention of formation of hard carbide particles in the soft ferrite matrix. After that, the HE behavior of the FSW processed steels has hardly been studied.

Though it is generally regarded that the hydrogen-induced embrittlement is a problem associated with high strength steel, in fact, a great number of studies has revealed that from low carbon steels to even high purity iron, they are all susceptible to the detrimental effect of hydrogen [20-26]. In this study, the sensitivity of the FSW processed low carbon steel to HE is investigated by the hydrogen cathodic charging method. The hydrogen induced damage including surface blistering and hydrogen-induced cracking is thoroughly investigated. The mechanical property of the SZ related to the blister or surface crack formation is investigated and compared with that of the base metal (BM) and the mechanism for hydrogen induced mechanical degradation is illustrated and discussed.

\section{Experimental details}

\subsection{Materials}

In this study, the as-received low carbon steel plates with a thickness of $0.8 \mathrm{~mm}$ were subjected to the FSW process by a stir-in-plate method using a load-controlled FSW machine. The chemical composition of the steel plate is shown in Table 1. A pin-less rotating tool made of $\mathrm{Si}_{3} \mathrm{~N}_{4}$ ceramic, which had a shoulder diameter of $12 \mathrm{~mm}$, was used during the welding process. The tool axis was tilted by $2^{\circ}$ with respect to the normal direction of the sample surface. The travelling speed of the rotating tool was kept constant at $280 \mathrm{~mm} / \mathrm{min}$ and the rotation speeds was $320 \mathrm{rpm}$. Argon shielding gas was used during the welding process to protect the SZ from oxidation.

\subsection{Cathodic hydrogen charging}

Fig. 1(a) shows the typical appearance of the friction stir welded sample. After welding, the dog-bone like tensile specimen and rectangular specimens for microstructural characterization were cut by an electrical discharge machine from the FSWed plates parallel to the welding direction, which are illustrated in Fig. 1(b). The rectangular specimen consisted of all the specific zones including the BM, HAZ, thermo-mechanically affected zone (TMAZ) and SZ, while the tensile specimen had a gauge length of $6 \mathrm{~mm}$, width of $3 \mathrm{~mm}$ and thickness of about $0.8 \mathrm{~mm}$. Thus the tensile specimen was completely inside the area of the SZ. Prior to hydrogen charging, the entire surface of the specimens was mechanically ground using emery papers to 4000 grade followed by polishing with a colloidal silica oxide polishing suspension, then rinsed and degreased with acetone. A thin stainless wire was electric resistance spot welded to the specimen which was placed into a charging cell filled with an aqueous solution of $0.5 \mathrm{M} \mathrm{H}_{2} \mathrm{SO}_{4}$ containing 1g/L thiourea and surrounded by a Pt wire. Since the specimen and the Pt wire were immersed into the solution in the cell, Pt dissolution and subsequent Pt re-deposition on the specimen might occur during the hydrogen charging. However, the Pt deposition exerted similar effect on the hydrogen charging behavior of the BM and SZ. The effect was very small and therefore was not considered in the present study. Hydrogen was introduced into the specimens by cathodic charging at the current density of $500 \mathrm{~A} / \mathrm{m}^{2}$ using a regulated direct current power supply under ambient temperature. For comparison, the specimens were hydrogen charged for different periods of 2, 4, 8 and 16 hours. After charging, the surfaces of the charged specimen were still very shiny and hydrogen blisters could be visually seen. The specimens were then immediately washed with distilled water and acetone. 
In order to determine the hydrogen content charged into the specimen, a Horiba EMGA-830 hydrogen content analyzer was employed for melt extraction. At least three specimens weighing about $0.2 \mathrm{~g}$ each were tested immediately after the hydrogen charging. The specimens were quickly heated up to their melting points temperatures for evaporating all gases, which were then taken by a nitrogen carrier gas through chemical reaction tubes to the analyzing units. The thermal conductivity of the carrier gas was measured and the software then calculated the hydrogen concentration of the sample based on the thermal conductivity variation. The estimated value represents the total amount of hydrogen in the material. However, very small amount of hydrogen may be lost in the process of sample preparation before being subjected to the hydrogen measurement.

\subsection{Microstructure and mechanical properties evaluation}

The microstructures of the FSWed joints as well as the BM before and after hydrogen charging were observed by optical microscopes (OM), a scanning electron microscope (SEM) attached with an electron backscatter diffraction (EBSD) system and a transmission electron microscope (TEM). For OM and SEM observation, the samples were mechanically polished followed by chemical etching using 3\% Nital solution. For the TEM observations, the samples were prepared by twin-jet electropolishing with a solution of $\mathrm{HClO}_{4}: \mathrm{CH}_{3} \mathrm{COOH}=1: 9$. The tensile testes for the uncharged and charged specimens were carried out using an Instron tensile machine at a cross-head speed of 0.5 $\mathrm{mm} / \mathrm{min}$. For the charged specimen, the tensile tests were started within 20 minutes after the charge finished in order for the hydrogen not to be released from the specimen. After tensile tests, the morphology of the fractured plane was characterized by SEM.

\section{Results and discussion}

\subsection{Microstructural characterization before hydrogen charge}

Fig. 2 shows the cross-sectional macrostructure of the welds including all the specific zones from the BM, HAZ, TMAZ to the SZ. From the overall image shown in Fig. 2(a), the boundary between the SZ and the BM was very clear due to the significantly refined microstructure in the SZ. Compared with the fusion welding of low carbon steel, in which the nugget area generally consists of solidified column or equiaxial crystals with a coarse grain structure, the SZ exhibits a basin-like shape with the top surface slightly wider than the bottom, which is the typical feature of the FSW processed sample caused by the metal flow driven by the tool shoulder. In addition, the tunnel-like defect usually caused by an insufficient heat input was not observed and a sound weld was obtained regardless of the pinless rotating tool used during the welding process. On the top surface of the weld, some flash formed at the edge of the SZ and some serrations caused by the revolution of rotating tool shoulder were observed. Fig. 2(b) shows the microstructure of the BM, which had an equiaxial grain structure. Fig. 2(c) shows the microstructure of a narrow area between the SZ and the BM as shown between the two dotted-lines in the figure, which is called the TMAZ. The TMAZ consists of a structure with deformed grains with the elongation direction parallel to the boarder of the SZ. The deformation of the grains was caused by the shear stress of the material flow, however, with much less extent than that in the SZ. As a result, none or only a partial dynamic recrystallization occurred in this area and the deformed grain structure reminded after the welding process. In addition, the HAZ can be hardly distinguished. Fig. 
2 (d) shows the microstructure of the SZ, which had a remarkably refined equiaxial grain structure caused by the recrystallization.

Fig. 3 shows the grain boundary maps of the microstructure in different specific zones of the FSWed joints, which were obtained from the EBSD measurement. The black, green and red lines denote the grain boundary with an angle larger than $15^{\circ}$, between $5^{\circ}$ and $15^{\circ}$, and between $2^{\circ}$ and $5^{\circ}$, respectively. The $\mathrm{BM}$ had a coarse equiaxial grain structure with an average grain size of about $16.9 \mu \mathrm{m}$, as shown in Fig. 3 (a). Generally the BM consists of high angle boundaries, with a small fraction of low angle boundary. Fig. 3(b) shows the area of the TMAZ, which is a narrow band with a width of about $200 \mu \mathrm{m}$ located between the SZ and HAZ. In the TMAZ, a significantly elongated grain structure was observed with the grains deformed parallel to the border of the SZ, which was caused by the shear stress from the rotating tool. In addition, a quite high fraction of the low angle boundary can be observed according to the colored lines, which also indicated that a high density of sub-grains or dislocations existed in this area. Fig. 3(c) shows the grain boundary map of the SZ, which has a remarkably refined equaxial grain structure with an average grain size of about $5.4 \mu \mathrm{m}$. The fraction of low angle boundary was small compared with that of that TMAZ, due to the occurrence of recrystallization and subsequent grain growth.

From the EBSD measurement, the misorientation angle histogram of the different specific zones were obtained and shows the same feature with other friction stir welds as illustrated in Fig. 4. It reveals that the TMAZ contains the highest number of low angle boundaries compared to the BM and SZ, due to the high degree of plastic deformation followed by nearly zero recrystallization associated with this region. However, the BM and SZ showed quite similar fraction of the low angle boundary. The SZ had a low fraction of low angle misorientation, which reveals that almost fully recrystallization occurred during the welding process.

\subsection{Microstructural characterization after hydrogen charge}

After welding, rectangular specimens were cut from the welds as shown in Fig. 1(b) and were hydrogen charged for different periods. Fig. 5(a), (b) and (c) show the surface appearance of the specimens after cathodic hydrogen charging for 2, 4 and 16 hours, respectively. Due to the occurrence of hydrogen-induced blistering, the boundary between the BM and SZ was clearly discernable and indicated by the dotted line. However, the TMAZ was too narrow and cannot be distinguished from the sample surface. The blisters formed on the surface of the BM of all the charged specimens, which can be visually seen. In addition, the blister density increased with the increase of the charging time. However, the blister formation was generally not confirmed on the surface of the SZ, except that a few small ones were observed on the SZ after hydrogen charging for 16 hours. This phenomenon reveals that the hydrogen induced blistering can be suppressed by the friction stir welding process.

The contents of the hydrogen introduced into the specimen by cathodic hydrogen charging were measured immediately after the charging was finished in order to minimize the release of the hydrogen from the specimen. The measurement was performed by rapidly heating the specimen to its melting point and detecting the released hydrogen content. The measured hydrogen content varied with the charging time for all the charged specimens, as shown in Fig. 5(b). The hydrogen concentration of the BM and the SZ before 
hydrogen charging was about $1.0 \mathrm{ppm}$ and $0.9 \mathrm{ppm}$, respectively. However, the BM and SZ showed quite different hydrogen permeation abilities, indicating that different amounts of hydrogen were introduced into the SZ of the welds depending on the varied microstructure. The hydrogen content in the BM rapidly increased with the increasing charging time and reached about $9.6 \mathrm{ppm}$ after 8 hours charging. However, the hydrogen content then increased slowly with a further increase in the charging time. The hydrogen content only increased to $10.2 \mathrm{ppm}$ after 16 hours of hydrogen charging. On the contrary, the hydrogen content in the sample made from the SZ shows gradually increased hydrogen content with the increase of hydrogen charging time. After 16 hours of hydrogen charging, only 2.3 ppm hydrogen was measured in the charged specimen.

Fig. 6 shows the surface appearance of the BM after hydrogen charging for different periods at a higher magnification. It reveals that blister formed on the surface of all the samples, regardless of the different hydrogen charge period. However, the number of the blisters increased with the increase in the hydrogen charging time. After hydrogen charging for 2, 4 and 16 hours, the number of the blister in average in one square millimeter was 105, 250 and 615, respectively. It is interesting to note that the blisters had different sizes ranging from several micrometers to about $100 \mu \mathrm{m}$. Generally, the blisters have a nearly round shape, however, some blisters with irregular shapes can also be distinguished as indicated by the arrow in Fig. 6 (a). The blister with an irregular shape generally had a relatively larger size and is supposed to be caused by the combination of two or more small blisters which were generated and developed at the same time. On the other hand, some small blisters were overlapped with the large blisters, in spite of the charging time. These small blisters were supposed to be formed after the development of the larger blister and show a similar size and shape with the small blisters distributed on the flat surface.

To obtain more detailed information on the blister characteristics, SEM observations of the surface of the specimen hydrogen charged for 16 hours were conducted. In order to illustrate the morphology of the blister clearly, the specimen was tilted with the surface normal $70^{\circ}$ declined to the electron beam direction. Fig. 7 shows the SEM images of the blister morphology. A clear boundary as indicated in Fig. 7(a) can be discerned between the blister formed area and blister-free area. The blister only formed outside the regions of the SZ and TMAZ, i.e., in the region of the HAZ and BM. However, the HAZ cannot be easily distinguished from BM due to their quite similar microstructures. In the BM, the blister density was high, which occupied about $30 \%$ of the total surface area. In addition, the size of the blisters varied from several $\mu \mathrm{m}$ to about $500 \mu \mathrm{m}$. Fig. 7 (b) shows one of the typical blisters with a relatively large size, on the edge of which a crack with a length of about $20 \mu \mathrm{m}$ can be observed.

It has been widely studied that the hydrogen induced damage including blisters and internal cracks appears in many kinds of materials in the absence of external stress if the hydrogen concentration is high enough. The internal cracks in iron and steel are believed to be induced by the combination of atomic hydrogen at a high concentration resulting in molecular hydrogen formation. Also, the propagation of internal cracks can be promoted by hydrogen gas in the voids or micro cracks that may be formed by plastic deformation [27-28]. In addition, the hydrogen atom is prone to diffuse to low free energy locations, for example, the interface of the matrix and inclusions such as MnS particles and cementite particles. When the pressure in the crack exceeds a critical value, the crack starts to grow [29]. The 
hydrogen induced damage has a great influence on the mechanical properties of the materials and can be the initial site of fracture under external stress.

The specimens with different charging times were cut along the transverse direction for the microstructural characterization. The cross-sectional microstructures were investigated as shown in Fig. 8. For all the specimens, the SZ can be distinguished due to its remarkably refined grain size. In the BM, the hydrogen-induced cracks can be found even after hydrogen charging for a very short time of less than 2 hours. In addition, the amount and the size of the hydrogen-induced cracks increased with the increase in the charging time. However, no crack was observed under the OM resolution in the SZ of all the samples, regardless of the hydrogen charging time. It is noteworthy that the hydrogen-induced crack was only observed on the border of the TMAZ after hydrogen charged for 16 hours, as indicated by the arrow in Fig. 8(c). The cracks formed along the boundary of the TMAZ both on advancing side and retreating side. Fig. 8 (d), (e) and (f) show the typical microstructures at higher magnification in the BM, SZ and TMAZ of the sample after hydrogen charging for 16 hours. In one square millimeter about fifteen large and small internal cracks formed in the BM. The larger ones had a length of about $100 \mu \mathrm{m}$ and a stepwise shape. Some closely distributed cracks were merged together as shown in the figure. In the SZ as shown in Fig. 8(e), no microstructural charges can be found even after a long charging period, which showed the same microstructure as that without a hydrogen charge. Fig. 8(f) shows the microstructure on the retreating side. Similar to the advancing side, totally about fourteen cracks continuously formed along the boundary of the TMAZ.

The microstructural feature of the hydrogen-induced crack was further investigated and as a typical example Fig. 9 (a) and (b) show the EBSD inverse pole figure (IPF) and image quality (IQ) map of some fully developed cracks distributed in the BM after hydrogen charging for 16 hours, which was observed from the cross-sectional plane. In all the EBSD maps, only a high angle boundary larger than 15 degree is shown in the figure. The black area indicates the cracks because no Kikuchi pattern could be generated. The crack was formed close to the surface and was believed to result in the formation of the surface blister as indicated in the figure. The fully developed cracks had a length of about $80 \mu \mathrm{m}$, much larger than the average grain size. In addition, the width of the crack was comparable to the grain size, which makes it difficult to understand the growth direction of the crack. According to the method suggested by Venegas et al. [30], the grains separated by the crack can be assumed to belong to the same grain under the condition that their misorientation is less than 3 degrees. It was found that the grains separated by the crack had a large misorientation, which revealed that the crack propagates along the high angle grain boundary. In addition, the cracked grains had a random orientation, indicating that the crack propagation was not along a preferential plane. Fig. 9(c) shows the SEM image of a partially developed crack, which was formed along the grain boundary. Fig. 9(d) shows the TEM images of some voids formed on the triangle grain boundary, as well as inside the grain. However, the micro-voids within the grains were quite small, which implied that the relatively lower hydrogen concentration therein resulted in a different contrast from the matrix under TEM observations. On the contrary, the voids formed on the grain boundary were larger and preferentially formed along the carbide or triangle grain boundaries. It is known that the grain boundary is an effective trap site for hydrogen migration. When the hydrogen enhanced the transportation of the lattice dislocation to the grain boundary, the hydrogen will be deposited within it. This dynamic process will therefore increase the hydrogen concentration as well as the pileup of dislocations near the grain 
boundary. When the internal stain energy increases to a critical value, the crack will nucleate and propagate along the grain boundary in order to relax the local stress [31-32]. On the other hand, the internal cracks can accommodate more hydrogen, which is also the reason that the measured hydrogen content is remarkably higher in the BM than in the SZ after hydrogen charging for the same period.

Fig. 10 shows the typical features of the hydrogen-induced damage in the SZ after hydrogen charging for 16 hours. The IPF orientation map and corresponding IQ map are shown in Fig. 10 (a) and (b), respectively. Compared with the $\mathrm{BM}$, the SZ showed a much refined microstructure and no obvious internal cracks were observed throughout the SZ. However, in some areas in the SZ, very few small voids can be observed on or near the grain boundaries. Simply from the color code of the orientation, it can be observed that the void formed along the high angle grain boundary. One low angle boundary indicated by an arrow shown in Fig. 10(b) revealed that the micro-void formed within the grain, but not along the low angle boundary. This is because the high angle boundary has a high energy more easily blocked the movement of dislocations than the low angle boundary. Fig. 10 (c) and (d) show the TEM images after the hydrogen was introduced into the SZ and was trapped along the interface between the carbide and the ferrite matrix. In the SZ, the dislocation density was higher than that in the BM, which can facilitate the diffusion of hydrogen atoms. The accumulation of hydrogen atoms increased the density of the vacancy and finally led to the formation of the micro-voids. Although the micro-voids formed in the SZ, which was similar to the formation of micro-voids observed in the BM after the hydrogen charging for the same period, the micro-voids formed in the SZ did not grow into large-sized cracks as those found in the BM. The suppression of the hydrogen-induced crack was supposed to be caused by the remarkable refinement of the grain size due to the recrystallization during the welding process. The influence of the grain size on the hydrogen-induced cracking has been described in some literatures. It was reported that a decrease in the grain size could decrease the propensity of hydrogen-induced cracking in iron or steel, in which both intergranular and transgranular cracking occurred [33-34]. This is because the grain size refinement can increase the strength level of the material and thus shows a higher resistance to the local stress caused by the accumulation of hydrogen atoms. Secondly, the stress concentration at the grain boundaries can be significantly reduced due to the increased boundary length. In addition, the impurity segregation can be decreased at the grain boundaries by increasing the grain boundary area.

Fig. 11 shows the IPF orientation map and IQ map of an area in the TMAZ. The TMAZ showed an elongated grain structure due to the shear stress of the rotating tool during the welding process. Several hydrogen-induced cracks with a length of about $50 \mu \mathrm{m}$ were continuously distributed along the boundary between the TMAZ and the HAZ. The cracks formed near the TMAZ had a smaller size than that in the BM, and cracks were observed only after hydrogen charging for 16 hours. This reveals that the BM is more susceptible to hydrogen-induced cracks, due to the coarse grain structure in the BM. In addition, the TMAZ had a higher fraction of low angle boundaries. The hydrogen-induced cracking was prone to form and propagate along the high angle boundaries, which has a higher energy than the low angle boundaries. Compared with the SZ, in which no obvious cracks could be found even after hydrogen charging for 16 hours, the TMAZ was more susceptible to hydrogen damage because that SZ had the smallest grain size among all the different specific zones. As for the fusion welded joints, the hydrogen-induced 
crack is generally very easy to occur in the coarse grained HAZ. However, as for the FSWed material, the HAZ had a much narrower region and showed no obvious increased grain size due to a welding temperature lower than the melting point, which implies that the FSWed material can have a longer service life when exposed to a hydrogen environment than the fusion welded counterpart.

\subsection{Mechanical properties}

Fig. 12 shows the tensile strain stress curves of the BM and SZ after hydrogen charging for different times. The tensile specimen made from the SZ showed a much higher yielding point and ultimate fracture strength due to the remarkably refined grain size. In addition, an obvious yielding drop after yielding with a feature of prominent upper and lower yield points can be observed, which is caused by the Cottrell atmosphere effect. For the BM, the yield drop phenomenon did occur due to the low dislocation density in the coarse grain structure. Singh et al.[21] studied the effect of hydrogen on the mechanical properties of low carbon steel by the cathodic hydrogen charge method and found that the yield drop disappeared after the hydrogen charging. However, the possible reason for the disappearance of the yield drop was not illustrated. In the present study, the yield drop on the strain stress curves of the SZ still can be clearly discerned even after hydrogen charging for 16 hours. It was also found that the plasticity of all the samples including the BM and SZ decreased with the increasing of hydrogen charging time. However, the BM showed a very sharp reduction in ductility from $48 \%$ to $12 \%$ only after 2 hour hydrogen charging. After the hydrogen charging for 16 hours, the plastic deformation of the BM decreased to only $2 \%$. On the contrary, the plastic deformation of the SZ decreased from 38\% to 28\% even after 16 hours of hydrogen charging. The photo of the fractured tensile specimens after 16 hours of hydrogen charging was also inserted in the Fig. 12. On the surface of the BM, a high density of blister can be observed easily. However, the SZ showed very smooth surface without any discernable blisters or cracks. In addition, the BM showed sudden fracture feature, while the SZ showed obvious necking and slipping bands on the surface close to the fracture area, which indicates the ductile deformation behavior of the specimen.

Fig. 13 shows the appearance of the side surface of the BM after the tensile tests, together with the morphologies of the fracture planes after hydrogen charging for different time. For the BM without any hydrogen charging, the specimen showed a very ductile feature and obvious necking can be observed from the side surface. The fracture plane showed a homogeneous dimple pattern indicating the significant plastic deformation of the material. However, after hydrogen charging even for only 2 hours, the ductility of the material had significantly deteriorated as shown in Fig. 13 (b). From the side surface observation, although the necking of the specimen was discernable, the necking was not obvious and the fractured plane obviously showed two kinds of fractured features. One was the sharp and smooth fractured plane, indicative of the quasi-cleavage fracture mode. The other was the dimple pattern surrounded by the dotted curved line in the figure, which confirmed that the specimen experienced some plastic deformation during the tensile tests. The area size of the dimple pattern was about $40 \%$ of the entire fractured area. After hydrogen charging for more than 4 hours, the necking of the specimen cannot be distinguished anymore from the side surface. In addition, some internal cracks were observed close to the fracture plane and the sample surface as shown in Fig. 13 (c). Also, the number of internal cracks increased with the increasing hydrogen charge time. On the fractured plane, the area size of the dimpled region decreased to about $10 \%$ of the entire fractured area. After 16 
hours of hydrogen charging, very large internal cracks were observed not only near the fracture plane and the sample surface, but also inside the specimen. No dimple pattern area can be discerned. Some large cracks can also be observed on the fractured surface, as indicated by the arrow in the Fig. 13(d).

Fig.14 shows the side surface of the SZ along the tensile direction after the tensile test together with the morphology of the fractured plane of the specimens for different hydrogen charging time. For all the specimens, the area reduction of the brittle fractured plane was obvious, indicative of the necking that occurred after uniform elongation of the specimens during the tensile tests. The morphologies of the fracture plane were quite similar for the specimen without hydrogen charging and that charged for 2 hours, both of which have a homogeneous fractured dimple pattern feature. For the specimens charged for 4 and 16 hours, although most of the fractured plane still exhibited the morphology of a dimple pattern, a very narrow cleavage fractured plane were observed close to the side surface. The cleavage plane indicated a brittle fracture feather and was considered to be caused by the introduction of hydrogen.

\section{Conclusions}

1) The hydrogen damage in low carbon steel can be suppressed by friction stir welding process, neither obvious hydrogen blister nor cracking was formed in the SZ of the hydrogen charged joints.

2) The BM is most susceptive to hydrogen blistering and hydrogen-induced cracking. After hydrogen charging for 16 hours, the hydrogen-induced cracking started to occur along the boundary of the TMAZ. However, only small voids were observed in the SZ even after hydrogen charging for 16 hours.

3) The BM showed a remarkably drop in plasticity after hydrogen charging even for a short time. After 16 hours of charging, the sample showed sudden failure after the yielding, while the SZ shows a plastic reduction from $38 \%$ to $28 \%$ after 16 hours of hydrogen charging.

\section{Acknowledgement}

The authors wish to acknowledge the financial support of a Collaborative Research Based on Industrial Demand “Heterogeneous Structure Control: Towards Innovative Development of Metallic Structural Materials” by Japan Science and Technology Agency (JST), the Global COE Programs from the Ministry of Education, Sports, Culture, Science, and a Grant-in-Aid for Science Research from the Japan Society for Promotion of Science and Technology of Japan, ISIJ Research Promotion Grant. 


\section{References:}

[1] M. Opiela. Hydrogen embrittlement of welded joints for the heat-treatable XABO 960 steel heavy plates. J. Achi. in Mater. Manu. Eng., 38 (2010) 41-48.

[2] J. Cwiek, A. Zielinski. Mechanism of hydrogen enhanced cracking of high-strength steel welded joints. J. Achi. in Mater. Manu. Eng. 18 (2006) 207-210.

[3] V. Olden, A. Alvaro, O.M. Akselsen. Hydrogen diffusion and hydrogen influenced critical stress intensity in an API X70 pipeline steel welded joint-Experiments and FE simulations. Inter. J. Hydro. Energy, 37 (2012) 11147411486.

[4] M.A. Arafin, J.A. Szpunar. A new understanding of intergranular stress corrosion cracking resistance of pipeline steel through grain boundary character and crystallographic texture studies. Corros. Sci. 51 (2009) 119-128.

[5] T. Dieudonne, L. Marchetti, M. Wery, J. Chene, C. Allely, P. Cugy, C.P. Scott. Role of copper and aluminum additions on the hydrogen embrittlement susceptibility of austenitic Fe-Mn-C TWIP steels. Corros. Sci. 82 (2014) 218-226.

[6] H.F. Jackson, C. San Marchi, D. K. Balch, B. P. Somerday. Effect of low temperature on hydrogen-assisted crack propagation in 304L/308L austenitic stainless steel fusion welds. Corros. Sci. 77 (2013) 210-221.

[7] G. Wang, Y. Yan, J.X. Li, J.Y. Huang, Y.J. Su, L.J. Qiao. Hydrogen embrittlement assessment of ultra-high strength steel 30CrMnSiNi. Corros. Sci. 77 (2013) 273-280.

[8] T. Neeraj, R. Srinivasan, J. Li. Hydrogen embrittlement of ferritic steels: Observations on deformation microstructure, nanoscale dimples and failure by nanovoiding. Acta Mater, 60 (2012) 5160.

[9] A. Nagao, CD Smith, M. Dadfarnia, P. Sofronis, IM. Robertson. The role of hydrogen in hydrogen embrittlement fracture of lath martensitic steel. Acta Mater, 60 (2012) 5182.

[10] W. M. Thomas, E.D. Nicholas, J.C. Needham, International Patent Application No. PCT/GB92/02203 (1991).

[11] R.S. Mishra, Z. Y. Ma. Friction stir welding and processing. Mater. Sci. Eng, R 2005, 50, 1-78

[12] R. Nandan, T. Debroy, H.K.D.H. Bhadeshia. Recent advances in friction stir welding- Process, weldment structure and properties. Prog. Mater. Sci, 2008, 53, 980-1023

[13]Y.F. Sun, H. Fujii. Investigation of the welding parameter dependent microstructure and mechanical properties in friction stir welded pure copper. Mater. Sci. Eng, A. 2010, 527, 6879-6886.

[14] H. Fujii, Y.F. Sun, H. Kato. Investigation of welding parameter dependent microstructure and mechanical properties in friction stir welded pure Ti joints. Mater. Sci. Eng-A, 2010, 527, 3386-3391.

[15] Y.S. Sato, A. Shiota, H. Kokawa. Evaluation of microstructure and properties in friction stir welded superaustenitic stainless steel. Sci. Tech. Weld. Join., 2009, 14, 202-209

[16] H. Fujii, L. Cui, N. Tsuji, M. Maeda, K. Nakata and K. Nogi. Friction stir welding of carbon steel. Mater. Sci. Eng. A, 2006, 429, 50-57.

[17] L. Cui, H. Fujii, N. Tsuji and K. Nogi. Friction stir welding of a high carbon steel. Scripta Mater., 2007, 56, 637-640. 
[18] Y. Morisada, H. Fujii, Y. Kawahito, K. Nakata and M. Tanaka. Three-dimensional visualization of materials flow during friction stir welding by two pairs of X-ray transmission system. Scripta Mater, 2011, 65, 1085-1088.

[19] S. Khodir, Y. Morisada, H. Fujii. Suppression of hydrogen-induced blisters in SK4 carbon steel alloy by friction stir processing. J. Mater. Sci. 2013, 48, 4313-4320.

[20] S. Wang, M.L. Martin, P. Sofronis, S. Ohnuki, N. Hashimoto, I.M. Robertson. Hydrogen-induced intergranular failure of iron. Acta Materilia, 69 (2014) 275-282

[21] S.K. Singh, B. Sasmal. Effect of ferrite grain size on tensile behavior of a hydrogenated low alloy steel. ISIJ international, 39 (1999) 371-379

[22] T. Neeraj, R. Srinivasan, J. Li. Hydrogen embrittlement of ferritic steels: Observations on deformation microstructure, nanoscale dimples and failure by nanovoiding. Acta Materialia, 60 (2012) 5160-5171.

[23] M Koyama, E. Akiyama, K. Tsuzaki, D. Raabe. Hydrogen-assisted failure in a twinning-induced plasticity steel studied under in situ hydrogen charging by electron channeling contrast imaging. Acta Materialia, 61(2013) 4607-4618.

[24] JL Davidson. Hydrogen-induced cracking of low carbon-low alloy steel weldments. Materials forum. 19 (1995) 35-51.

[25] I. Maroef, D.L. Olson, M. Eberhart, G.R. Edwards. Hydrogen trapping in ferritic steel weld metal. Inter. Mater. Rev, 47 (2002) 191-223.

[26] J.K.L. Lai, K.H. Lo, C.H. Shek. Stainless steels: An introduction and their Recent Developments. Bentham Science Publishers, 2012.

[27] Garofalo F, Chou YT, Ambegaokar V. Effect of hydrogen on stability of micro crackes in rion and steel. Acta Mater. 1960; $8: 504-512$

[28] H.F. Jackson, K.A. Nibur, C.S. Marchi, J.D. Puskar, B.P. Somerday. Hydrogen-assisted crack propagation in 304L/308L and 21Cr-6Ni-9Mn/308L austenitic stainless steel fusion welds. Corros. Sci. 60 (2012) 136-144.

[29] Schlogl SM, Van der Giessen E. Computational model for carbon diffusion and methane formation in a ferritic steel during hydrogen attack. Scripta Mater., 2002; 46 : 431-436.

[30] V. Venegas, F. Caleyo, J. M. Hallen, T. Baudin and R. Penelle. Role of crystallographic texture in hydrogeninduced cracking of low carbon steels for sour service piping. Metall.Mater. Trans, A, 2007, 38, $1022-1031$.

[31] A. Ramasubramaniam, M. Itakura, M. Ortiz, E.A. Carter. Effect of atomic scale plasticity on hydrogen diffusion in iron: Quantum mechanically informed and on-the-fly kinetic Monte Carlo simulations. J. Mater. Res. 23 (2008) 2757-2773.

[32] R. Kirchheim. Interaction of hydrogen with external stress fields. Acta Metall. 34 (1986) 37-42.

[33] I.M. Bernstein, B.B. Rath. Role of grain boundary solutes and structure on yielding and intergranular cracking of iron. Metall. Trans., 4 (1973) 1545

[34] R. Garber, IM Bernstein, A.M. Thompson. Hydrogen assisted ductile fracture of spheroidized carbon-steels. Metall. Trans. A, 12 (1981) 225-234. 


\section{Captions of Tables and Figures}

Table 1. Chemical composition of low carbon plates (wt. \%)

Fig. 1 (a) Appearance of the friction stir welded plates; and (b) Schematic map showing the specimen preparation method.

Fig. 2 (a) OM images showing the cross-sectional macrostructure of the welds and microstructure of (b) BM; (c) TMAZ and (d) SZ.

Fig. 3 EBSD grain boundary map showing the microstructure of (a) BM; (b) TMAZ; and (c) SZ

Fig. 4 Misorientation angle distribution of (a) BM; (b) TMAZ; and (c) SZ

Fig. 5 (a) OM images showing the surface appearance; and (b) the hydrogen contents in the BM and SZ of the welds with different hydrogen charging times.

Fig. 6 OM images showing the blister morphology on the surface of the BM for different hydrogen charging time. (a) 2 hours, (b) 4hours, and (c) 16 hours

Fig. 7 SEM images showing the surfacial appearance of the charged specimen titled $70^{\circ}$ with the beam direction. (a) boundary between BM, TMAZ and SZ; (b) crack formed along the edge of the blister on BM.

Fig. 8 OM images showing the cross-sectional macrostructure of the sample after hydrogen charging for (a) 2h; (b) 4h; and (c) 16h. Hydrogen-induced internal crack in the steel weld after hydrogen charging for $16 \mathrm{~h}$. (d) BM; (e) SZ and (f) crack formed in TMAZ on RS side.

Fig. 9 (a) EBSD-IPF map and (b) IQ map showing the fully developed cracks through both the transgrandual and intergrandual modes; and (c) SEM and (d) TEM images showing the hydrogen induced cracks formed along the grain boundary of the BM.

Fig. 10 (a) EBSD IPF map and (b) IQ map showing the voids near the grain boundary; and (c, d) TEM images showing the hydrogen-induced micro-void formation along the grain boundary in the SZ.

Fig. 11 (a) IPF; and (b) IF map showing the HIC formation along the TMAZ of the sample after hydrogen charging for 16 hours

Fig. 12 Tensile strain-stress curves of the BM and SZ after hydrogen charging for different periods of time

Fig. 13 Effect of hydrogen charging time on the appearance of the side surface and the corresponding fractural morphology of the BM after the tensile tests. Hydrogen charging for (a, a') 0, (b, b’) 2, (c, c') 4, and (d, d') 16 hours

Fig. 14 Effect of hydrogen charging time on the side surface and the corresponding fractural morphology of the SZ after the tensile tests. Hydrogen charging for (a, a') 0, (b, b') 2, (c, c') 4, and (d, d') 16 hours 
Table.1

\begin{tabular}{c|ccccc}
\hline \multirow{2}{*}{ Steel type } & \multicolumn{6}{|c}{ Chemical composition (mass\%) } \\
\cline { 2 - 6 } & $\mathbf{C}$ & $\mathbf{M n}$ & $\mathbf{P}$ & $\mathbf{S}$ & $\mathbf{F e}$ \\
\hline low carbon steel & 0.12 & 0.50 & 0.40 & 0.045 & Bal. \\
\hline
\end{tabular}




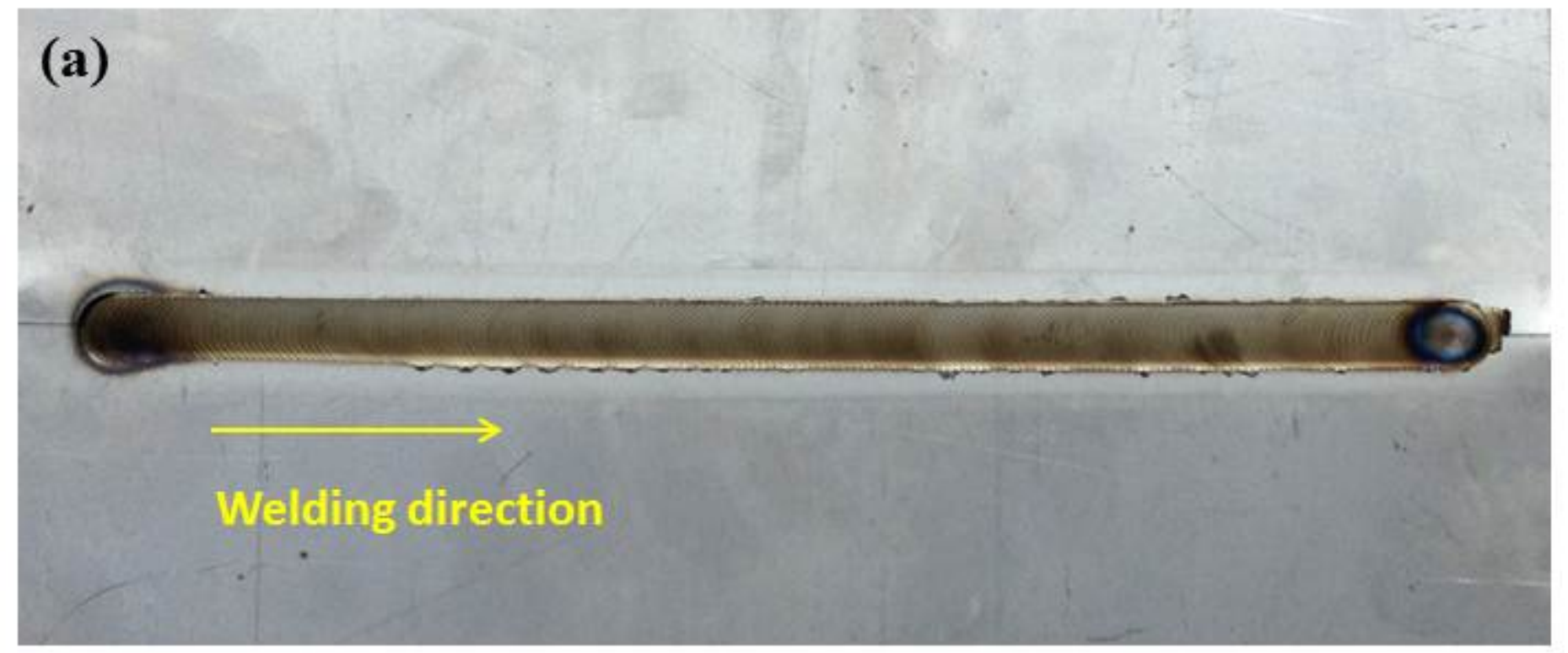

(b)

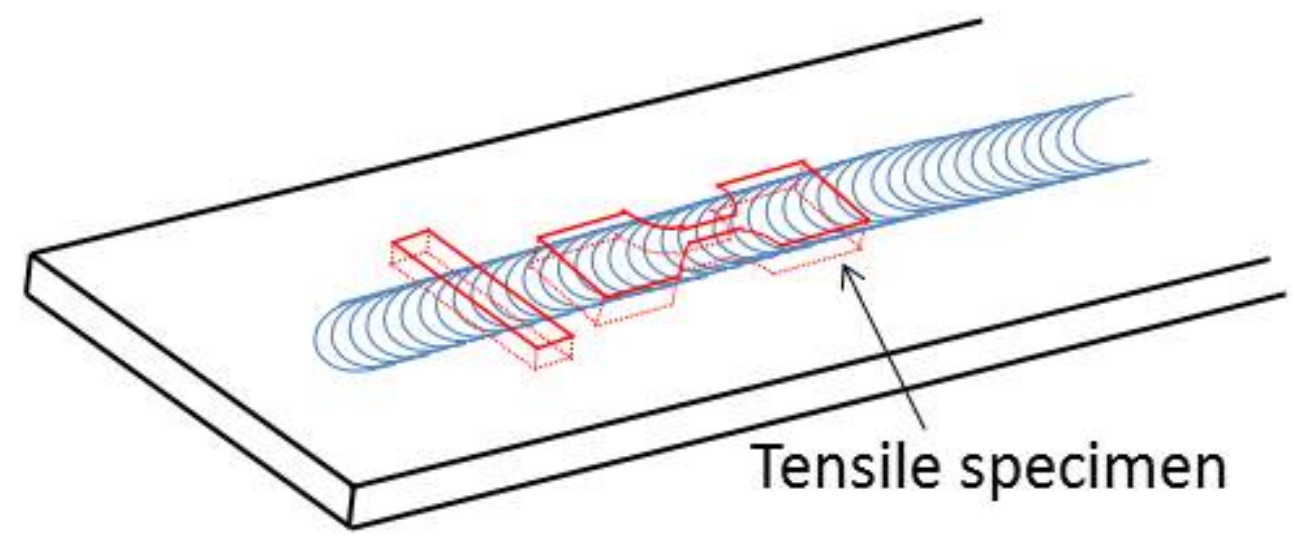

Figure 1 

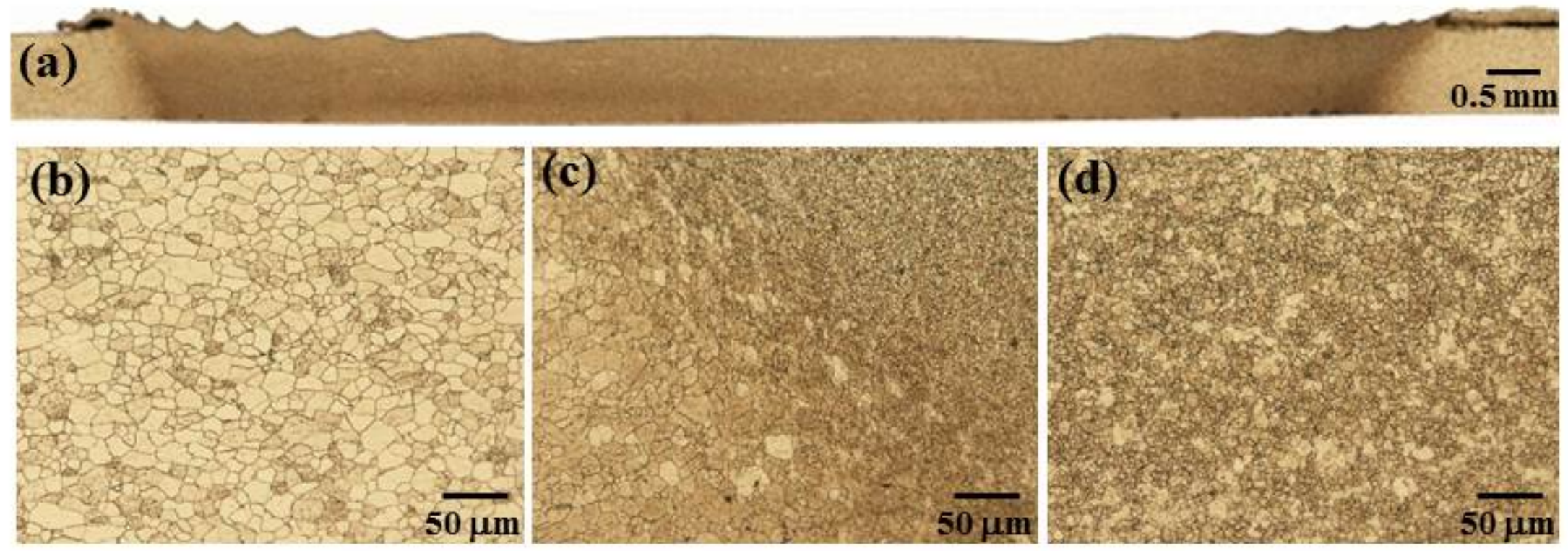

\section{Figure 2}




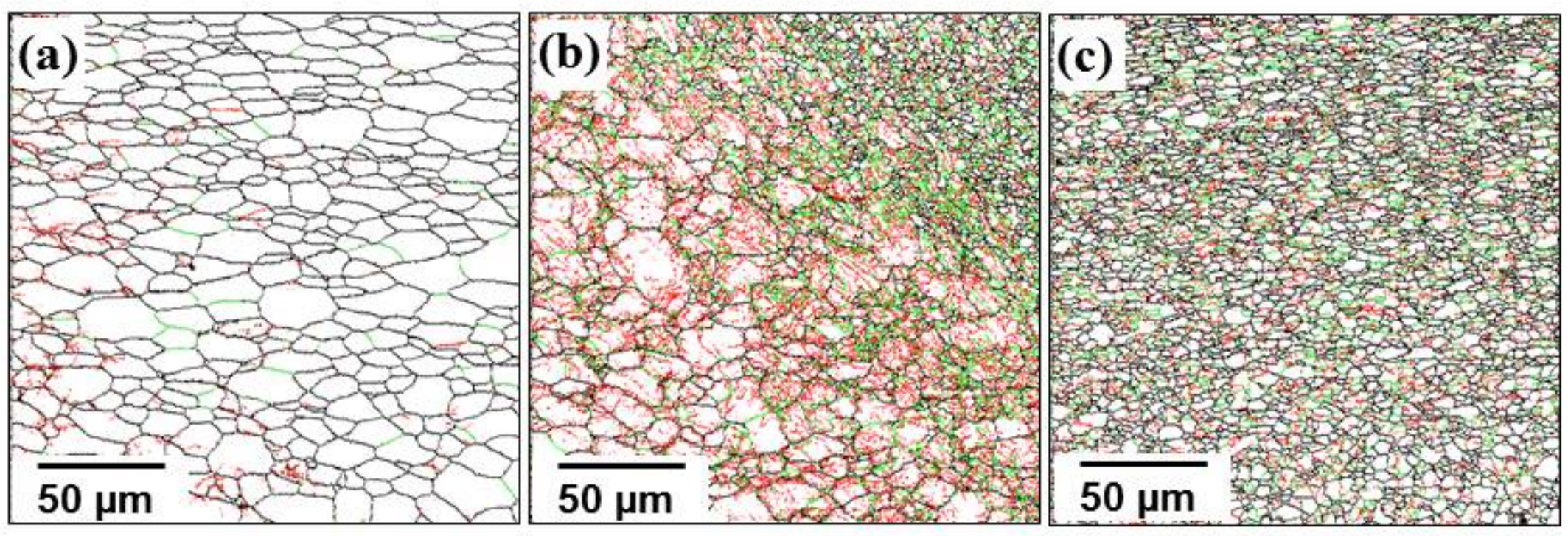

Figure 3 


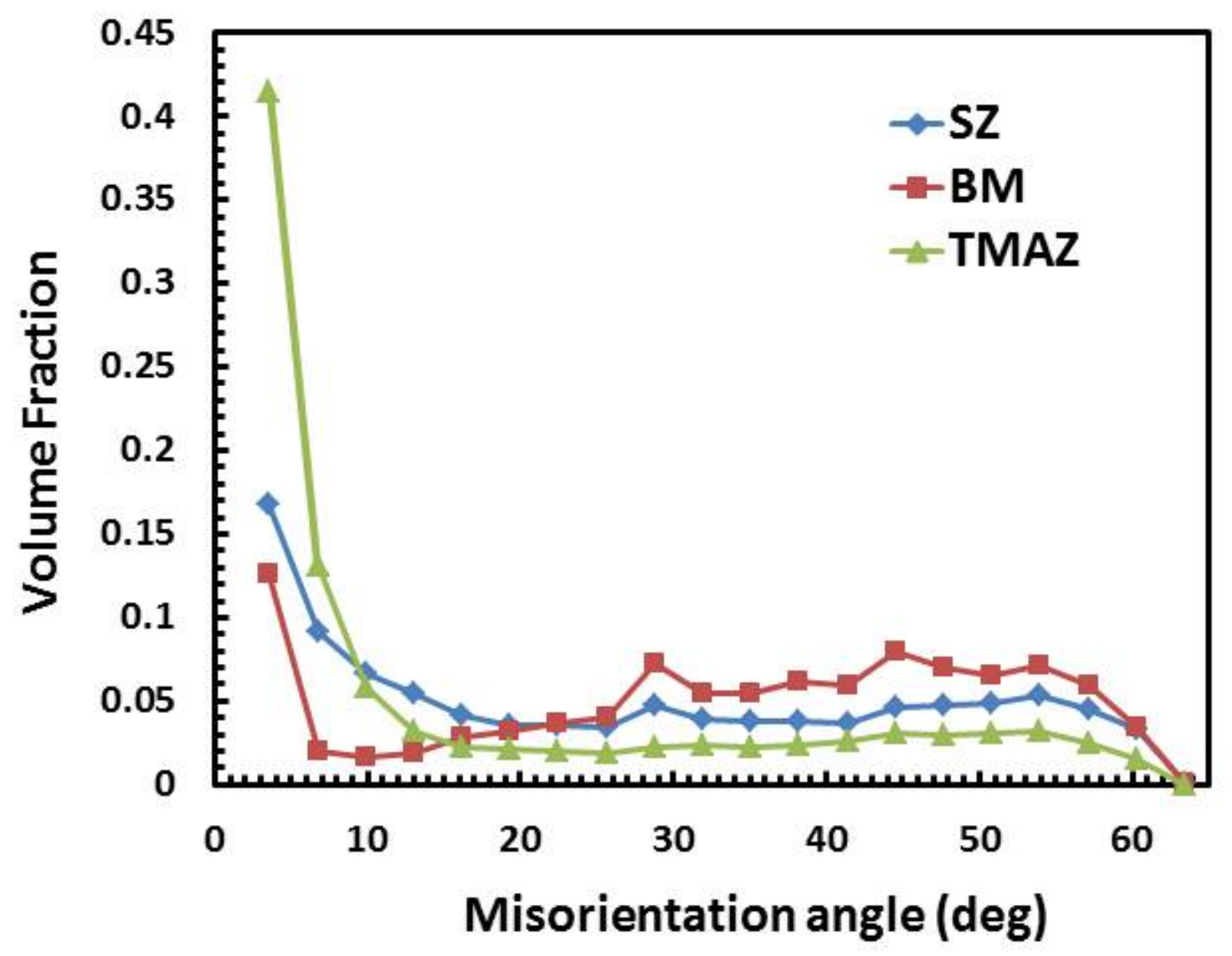

Figure 4 

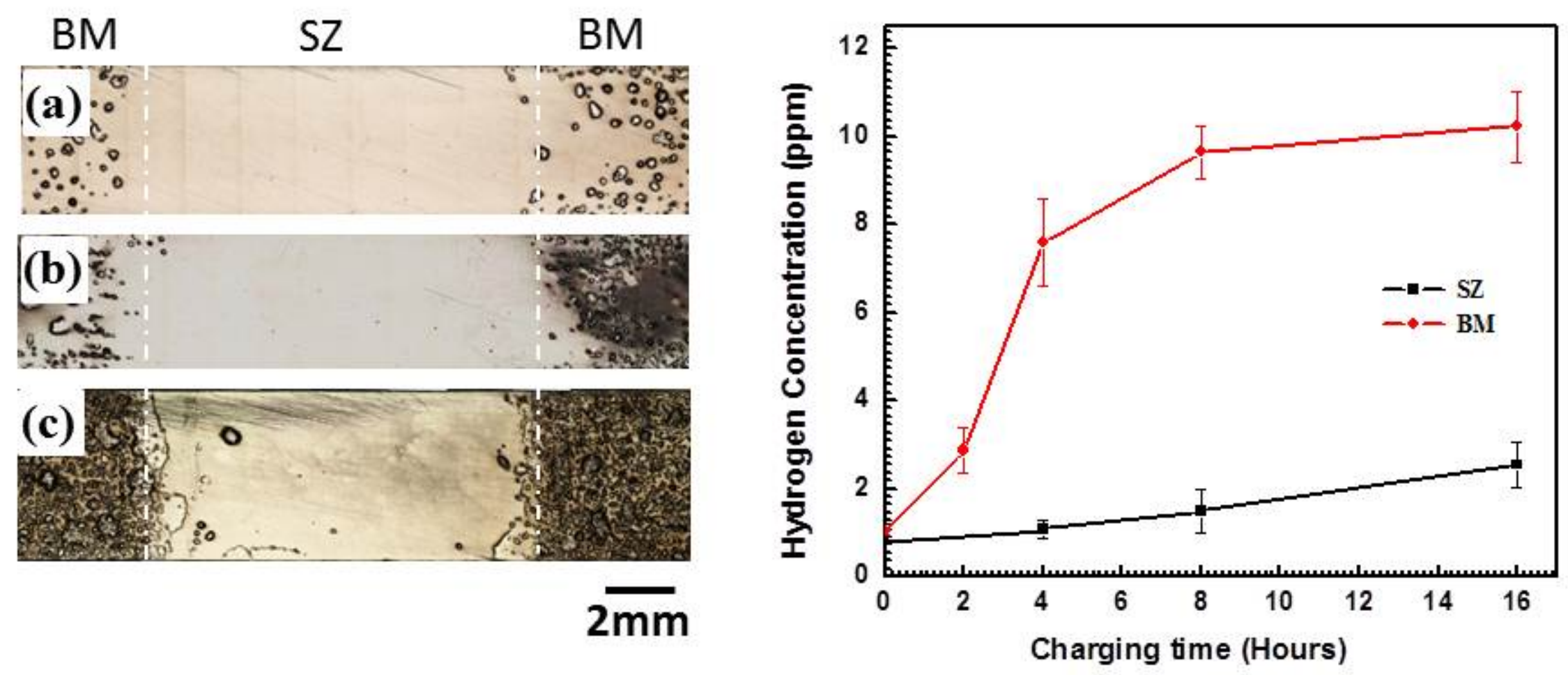

(d)

\section{Figure 5}




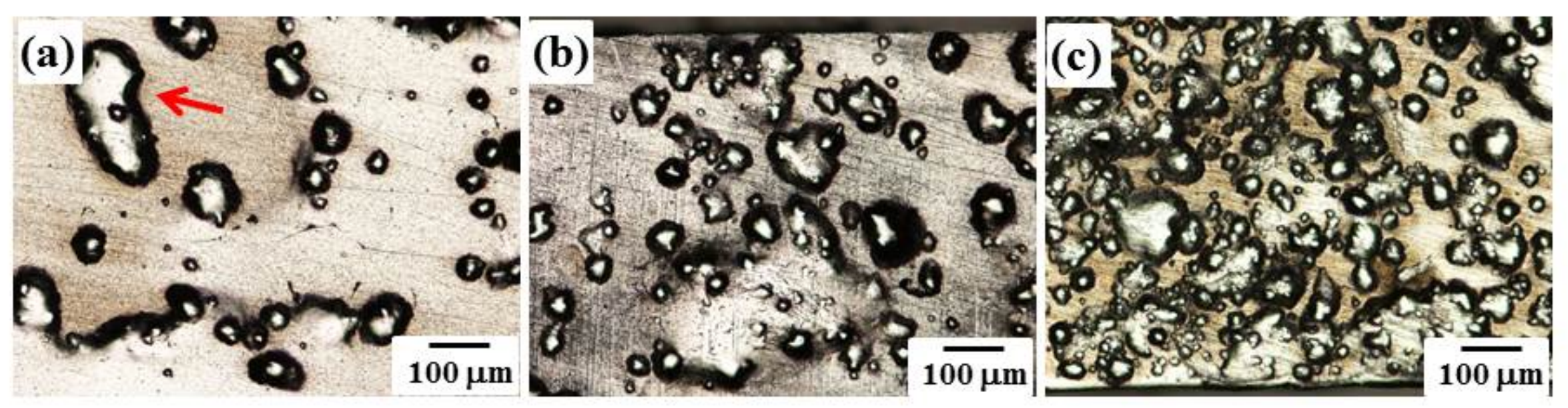

Figure 6 


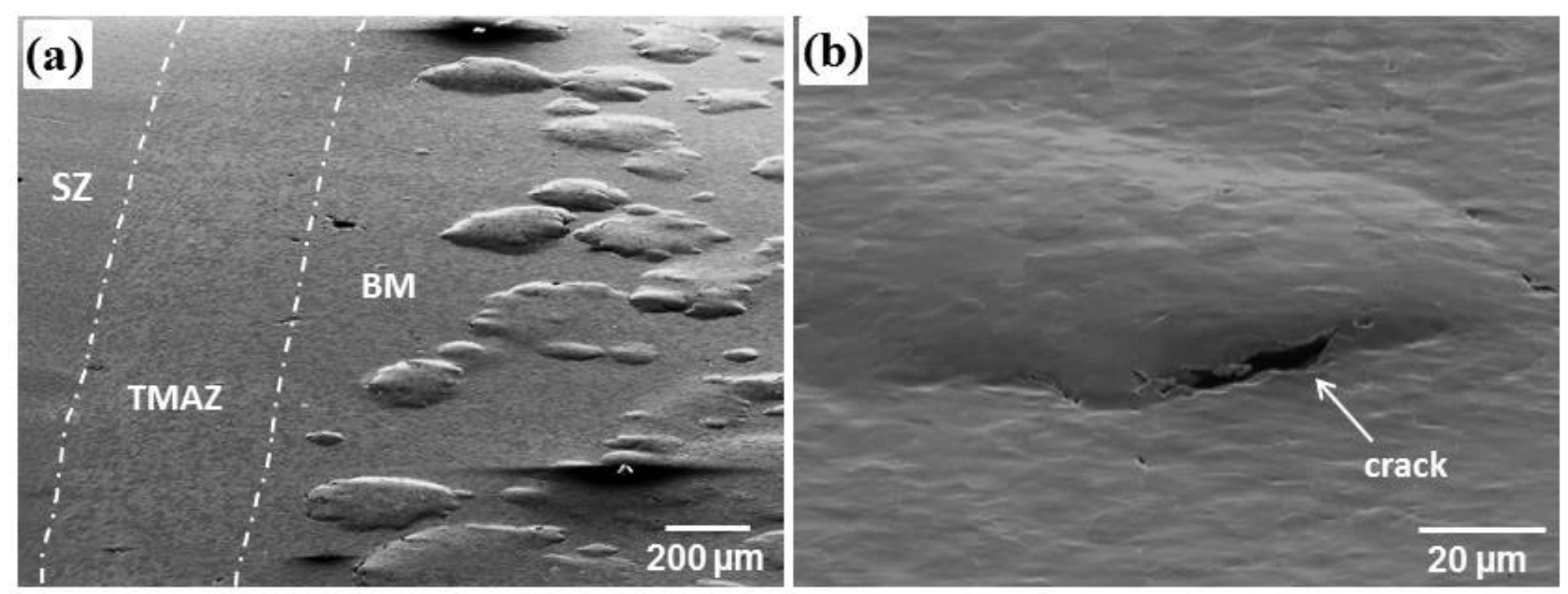

Figure 7 

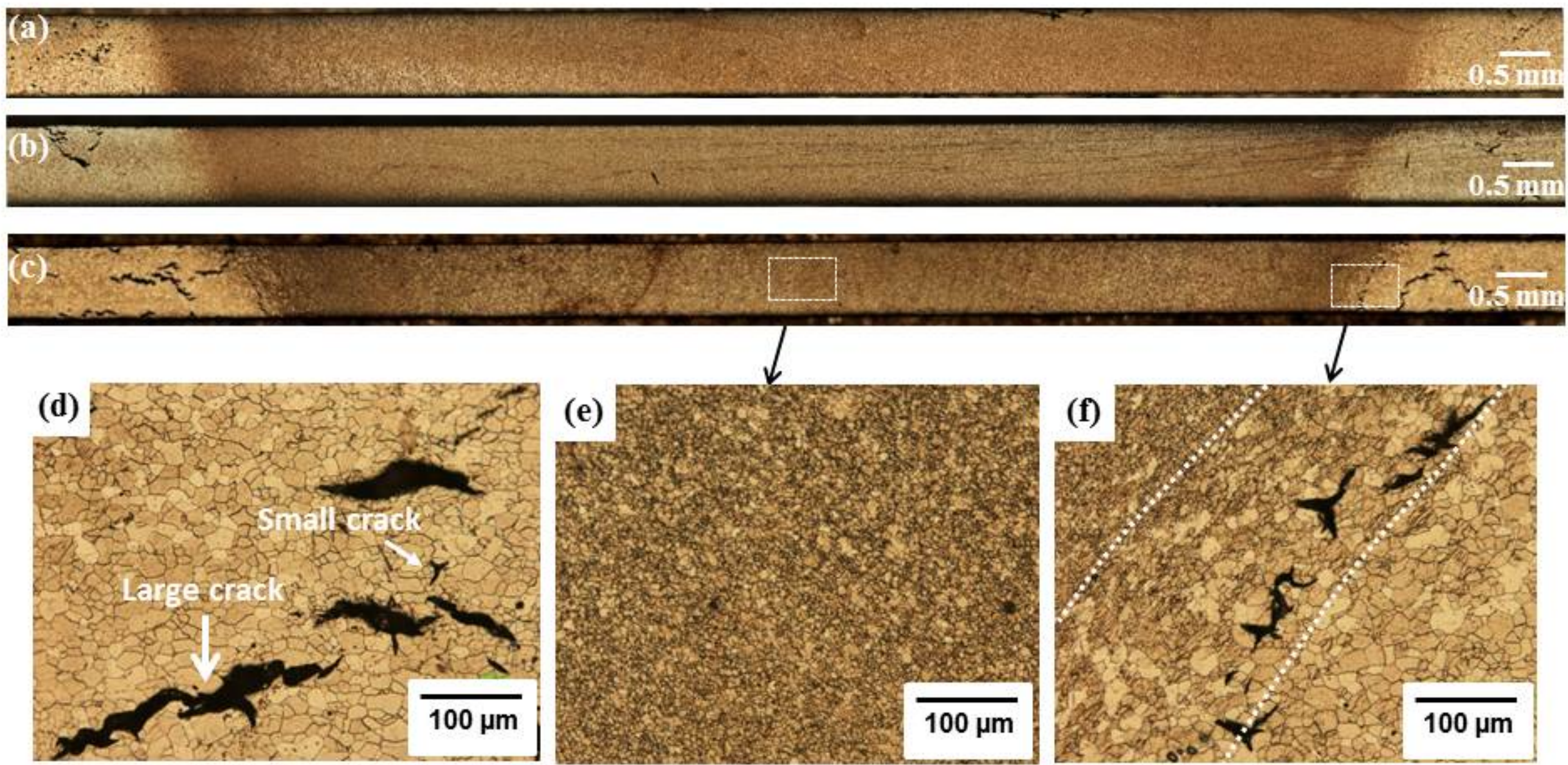

\section{Figure 8}



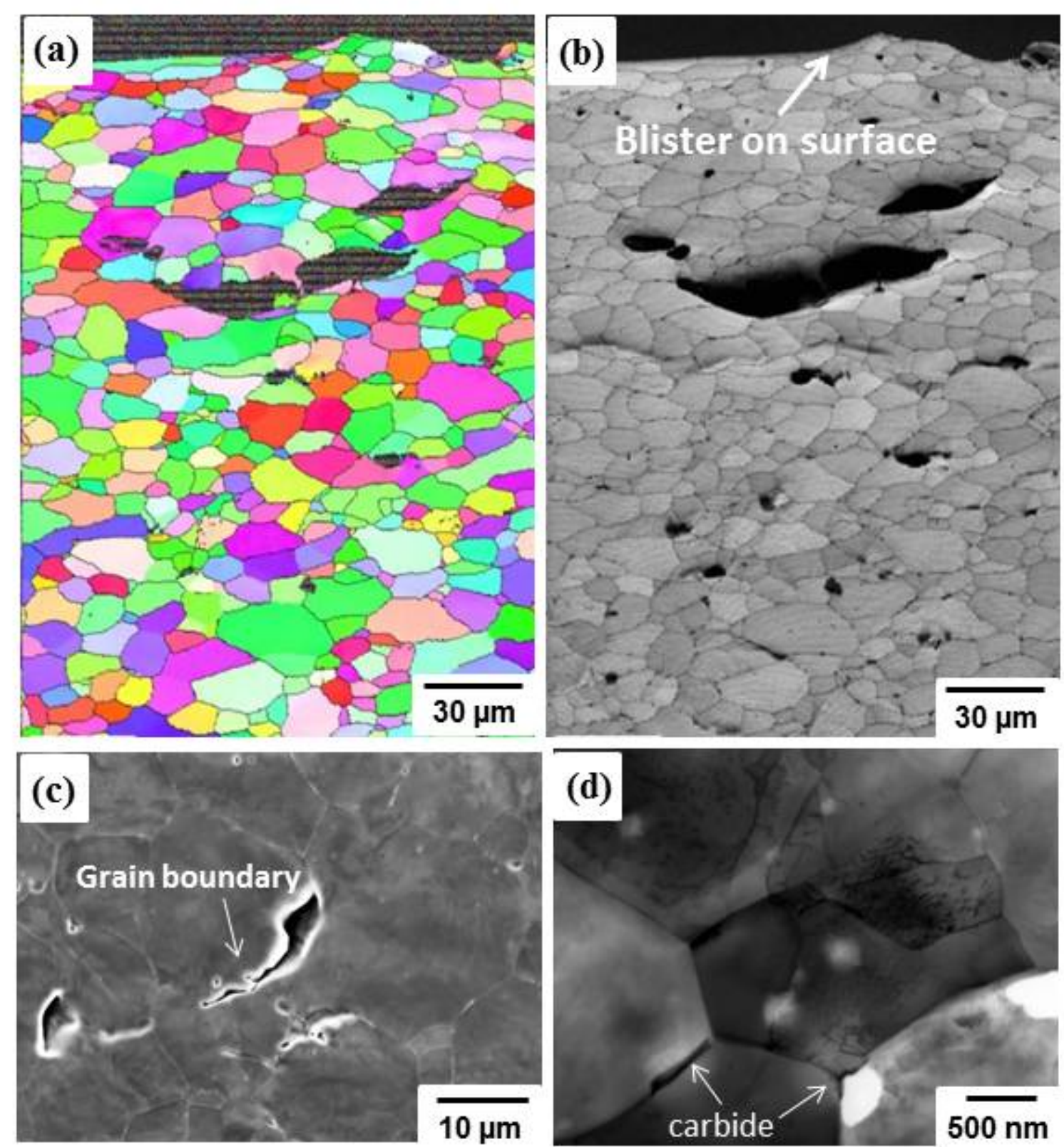

(d)

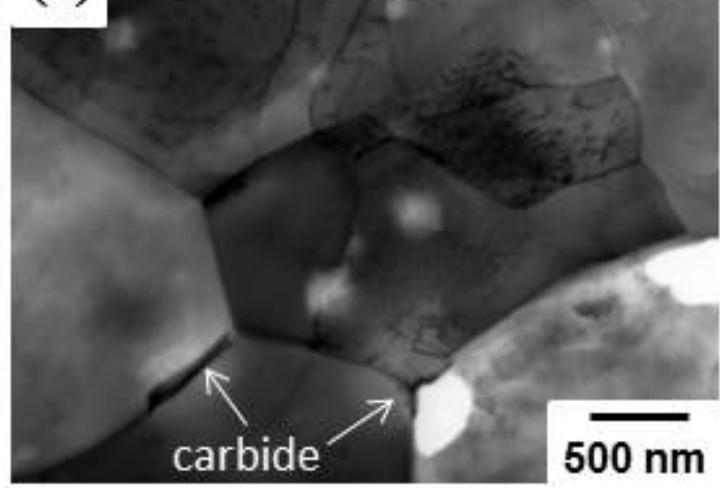

\section{Figure 9}



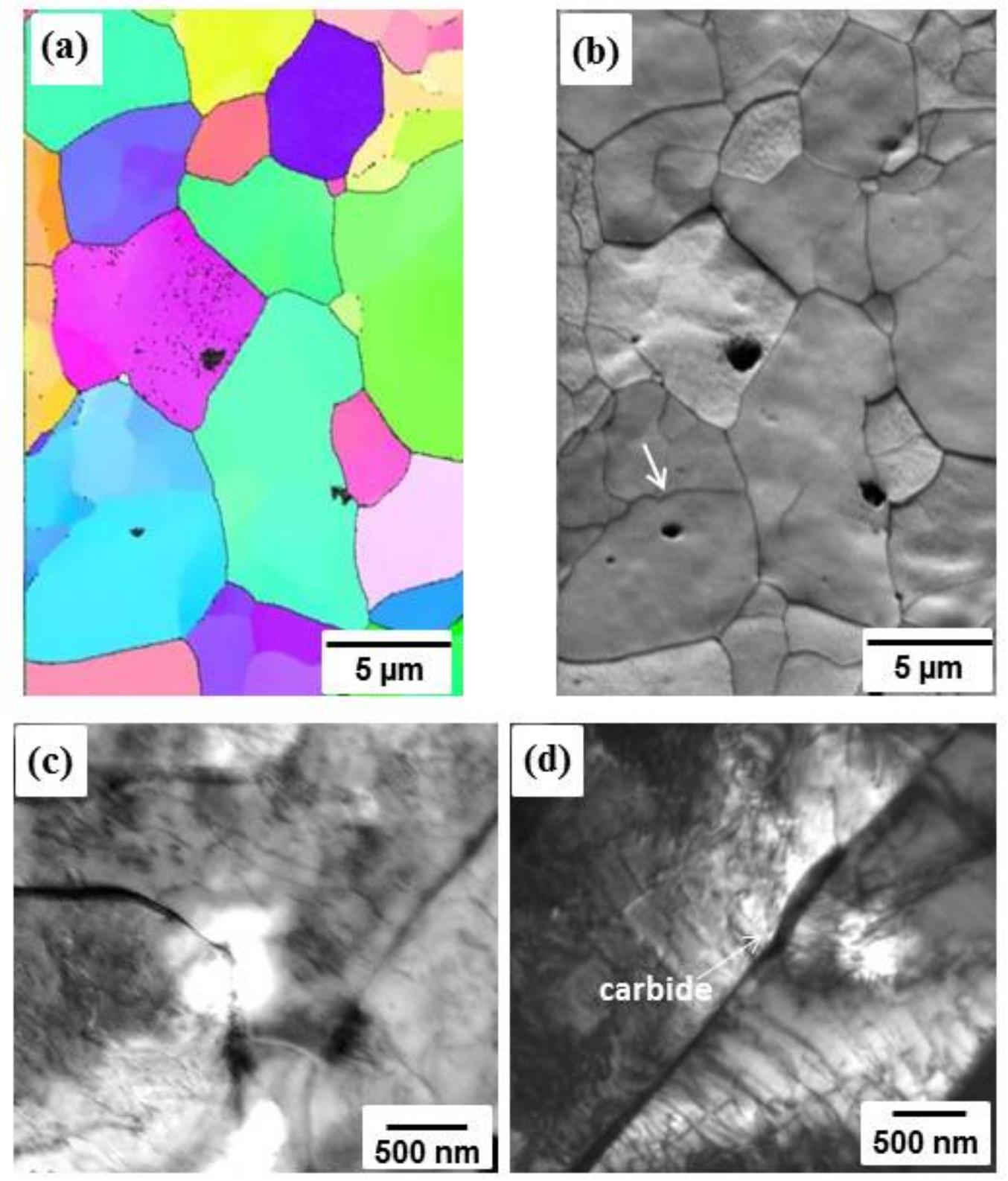

Figure 10 

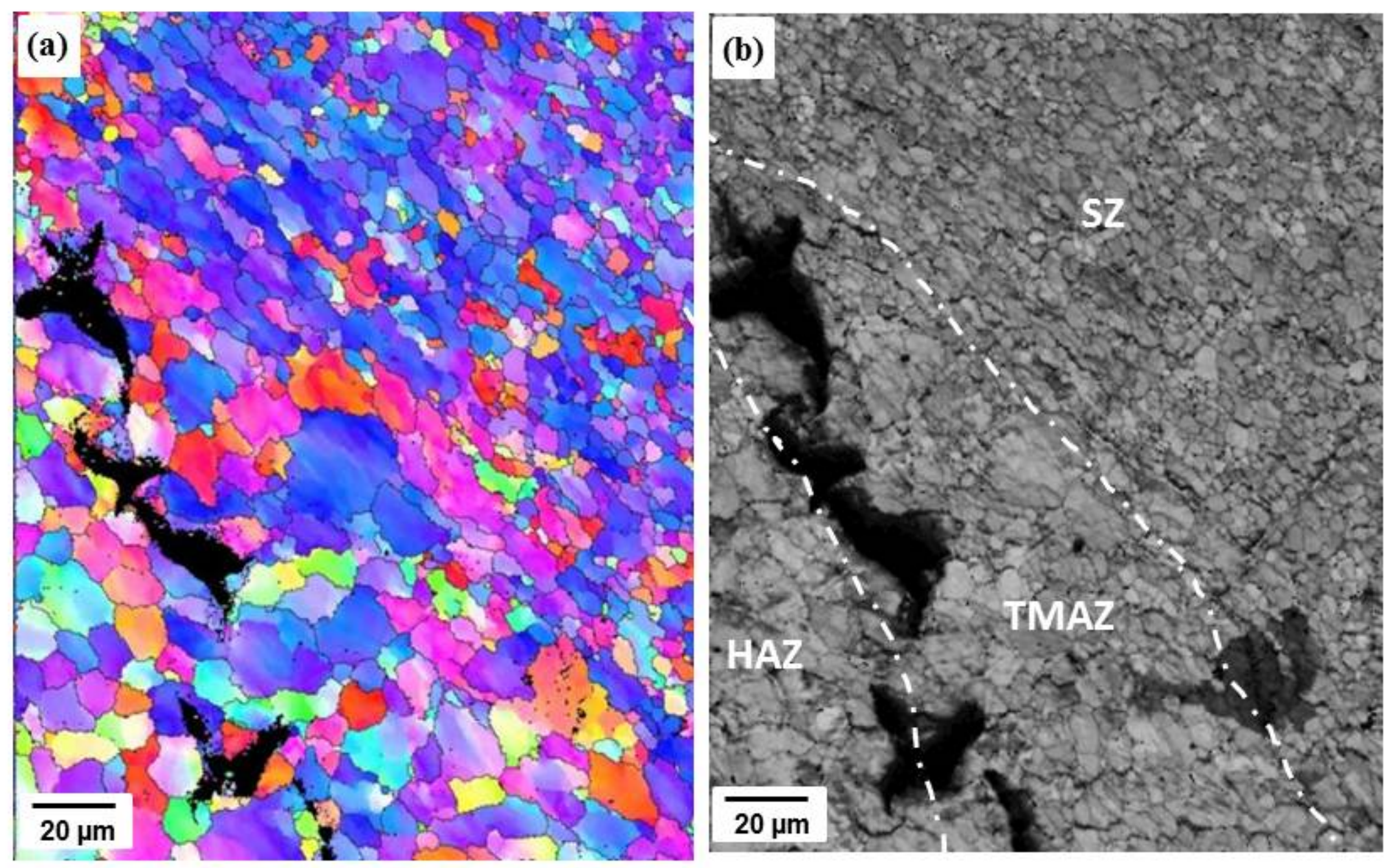

Figure 11 


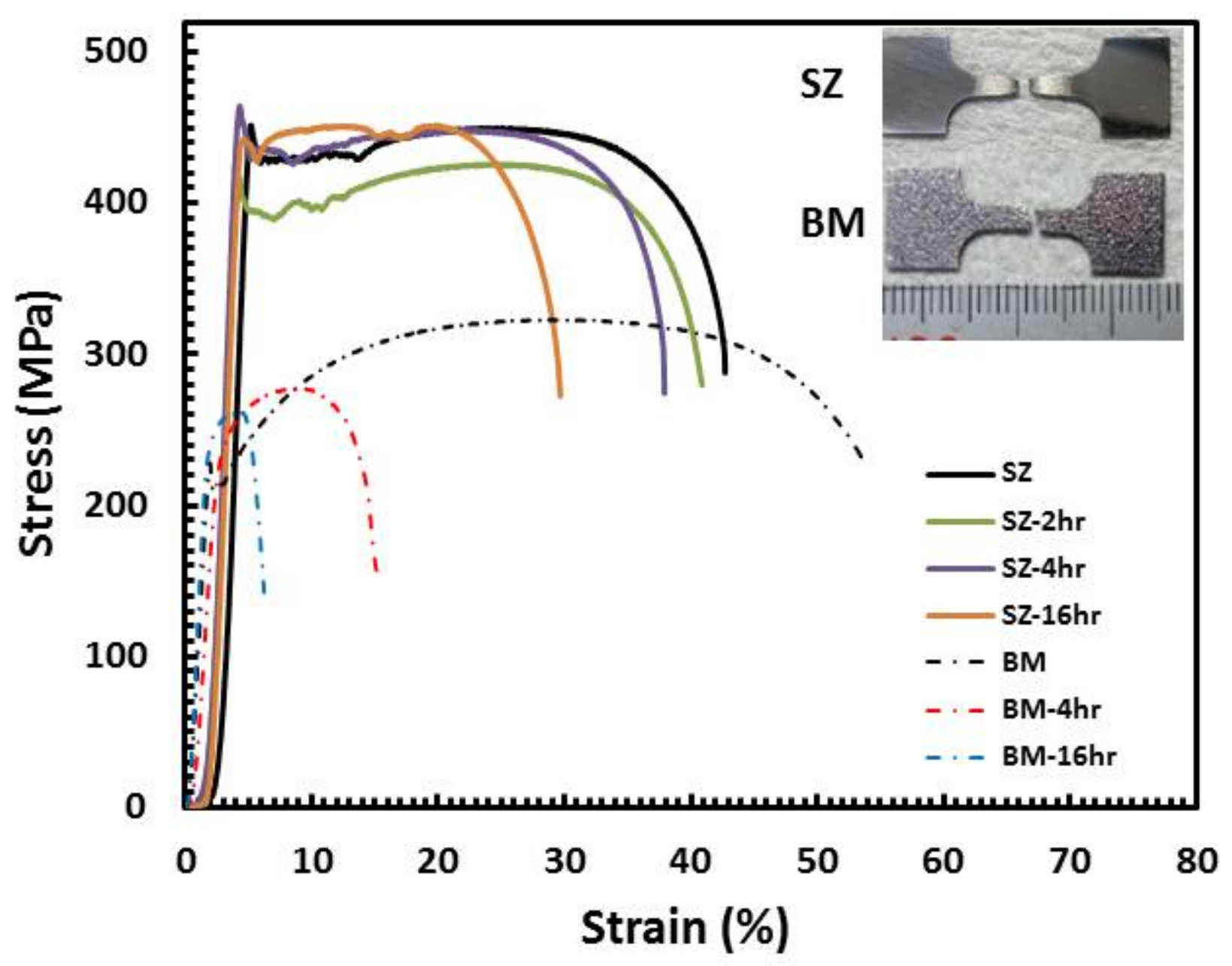

Figure 12 

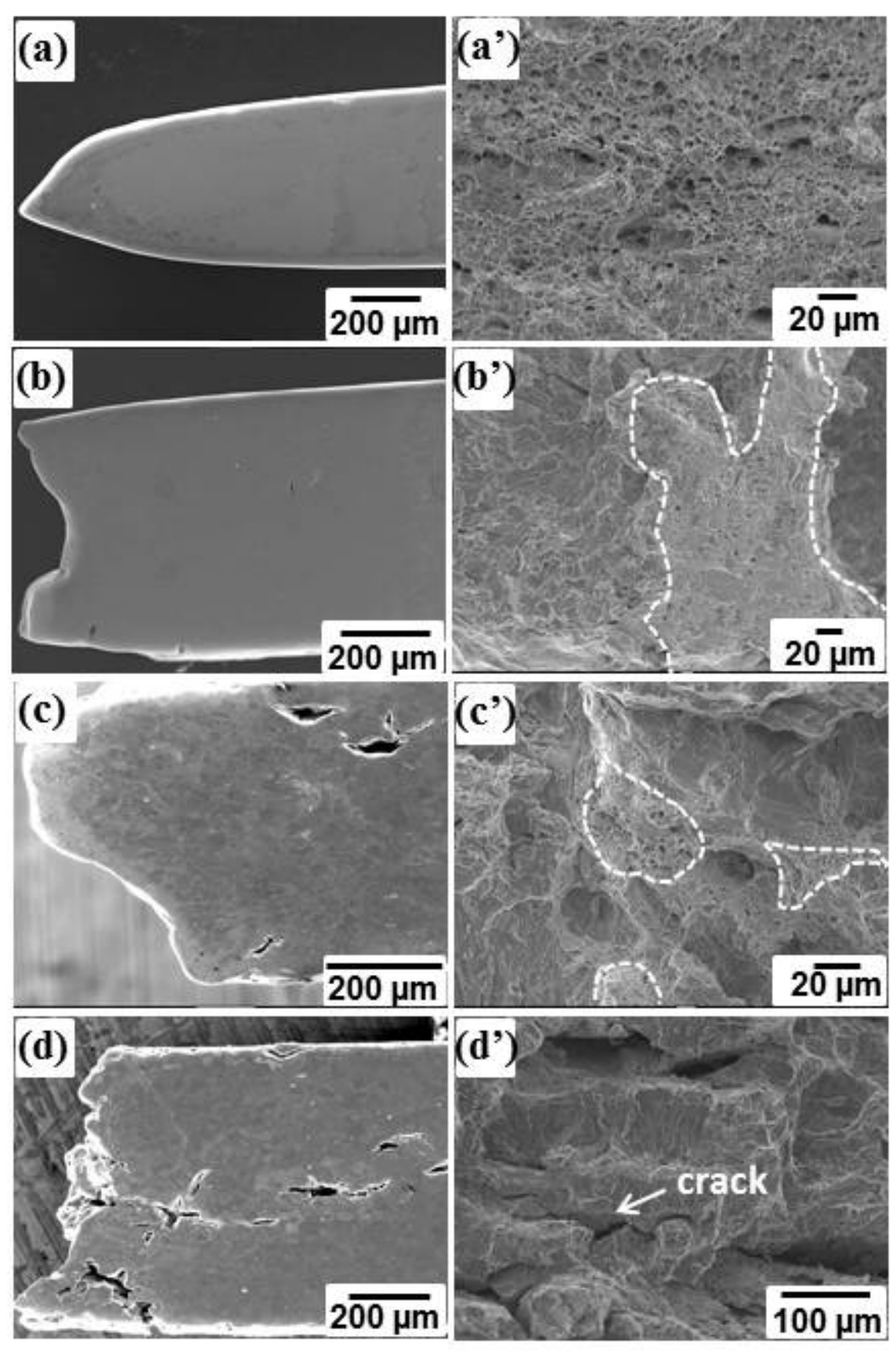

\section{Figure 13}




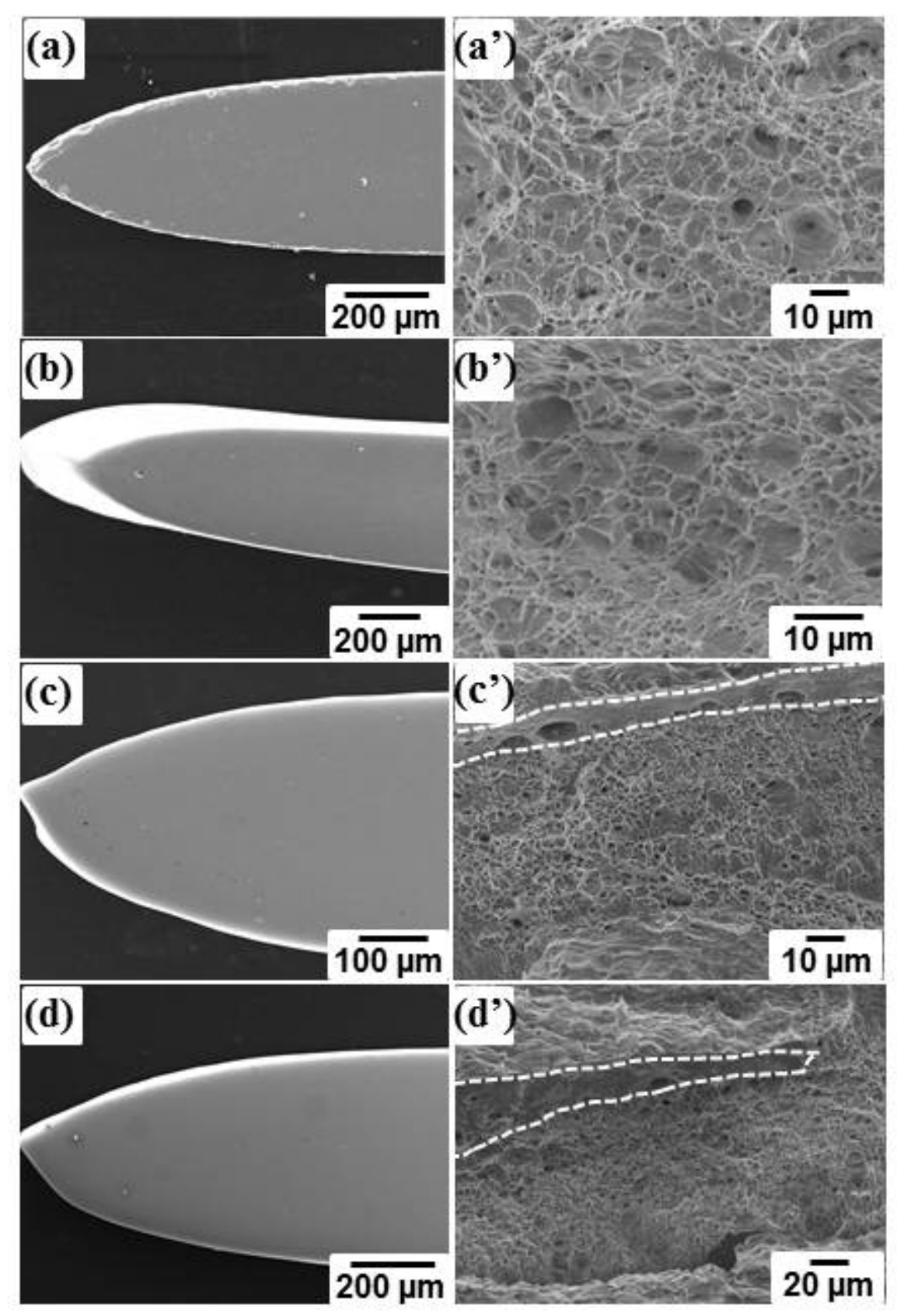

\section{Figure 14}

